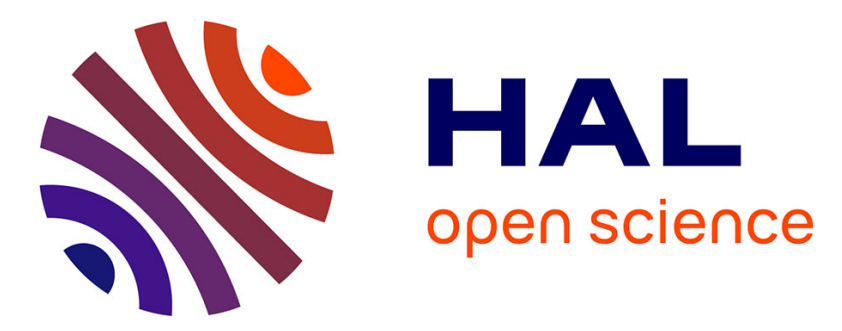

\title{
A new class of spirocyclic photochromes reacting with light of both UV and visible ranges
}

Laura Bekere, Nina Larina, Vladimir Lokshin, Arkady Ellern, Mark Sigalov, Vladimir Khodorkovsky

\section{- To cite this version:}

Laura Bekere, Nina Larina, Vladimir Lokshin, Arkady Ellern, Mark Sigalov, et al.. A new class of spirocyclic photochromes reacting with light of both UV and visible ranges. New Journal of Chemistry, 2016, 40 (8), pp.6554-6558. 10.1039/C6NJ00666C . hal-03500738

\section{HAL Id: hal-03500738 \\ https://hal.science/hal-03500738}

Submitted on 22 Dec 2021

HAL is a multi-disciplinary open access archive for the deposit and dissemination of scientific research documents, whether they are published or not. The documents may come from teaching and research institutions in France or abroad, or from public or private research centers.
L'archive ouverte pluridisciplinaire HAL, est destinée au dépôt et à la diffusion de documents scientifiques de niveau recherche, publiés ou non, émanant des établissements d'enseignement et de recherche français ou étrangers, des laboratoires publics ou privés. 
Received 00th January 20xx Accepted 00th January 20xx

DOI: $10.1039 / x 0 x \times 00000 x$

www.rsc.org/

Condensation of bindone with cynnamic aldehydes produces cyclic isomers instead of the expected colored merocyanine dyes. These compounds exhibit unprecedented photochromic behavior: the formation of the colored open forms is observed upon irradiation by light of any wavelength between 254 and $642 \mathrm{~nm}$.

During the past decades, merocyanine $(\mathrm{MC})$ dyes $^{1}$ are the focus of numerous researches owing to the importance of this type of organic dyes in different fields of materials science, such as nonlinear optics, ${ }^{2}$ solar cells, ${ }^{3}$ thin-film transistors ${ }^{4}$ and biological applications. ${ }^{5}$ A special group of merocyanines is related to photochromism. Thus, such important classes of known spiroheterocyclic photochromes ${ }^{6}$ as spiropyrans, spirooxazines, chromenes and others form merocyanines as a result of the UV light induced cleavage of the $\mathrm{C}-\mathrm{O}$, or more rarely $\mathrm{C}-\mathrm{C}$, bonds. ${ }^{7,8}$ These merocyanines are usually less stable than the initial cyclic forms and undergo more or less rapid cyclization and the respective color loss. Depending on the structural factors, temperature or media, the equilibrium between the cyclic and merocyanine forms can be shifted toward the latter partially or completely. ${ }^{9}$ The stable MC can be isolated and characterized. ${ }^{10}$ Some of them can exhibit negative (reverse) photochromism, ${ }^{11}$ that is the reversible cyclization upon irradiation by visible light. Recently, the important for the biomedical applications ability of photochromes to react with visible light was demonstrated on the example of substituted azobenzenes. ${ }^{12}$

More than a decade ago, we found that the product of the reaction between bindone (1) and $p$-dimethylaminocinnamic aldehyde (2a) is not the expected colored merocyanine $\mathbf{4 a}$, but its cyclic isomer $3 a .^{13}$ In solution or polymer matrix, irradiation

\footnotetext{
a. Aix Marseille Université, CNRS, CINaM UMR 7325, 13288, Marseille, France.

Email:khodor@cinam.univ-mrs.fr

b. Chemistry Department, lowa State University, 1711 Gilman Hall, Ames, IA, 50011, USA.

c. Department of Chemistry, Ben Gurion University of the Negev, 84105, Beer Sheva, Israel.

†Electronic Supplementary Information (ESI) available: Synthetic procedures, details on X-ray structure determinations and a full table of the shortened C...O
} distances, ${ }^{1} \mathrm{H}$ nmr spectra, calculations summary. See DOI: 10.1039/x0xx00000x of $3 a$ at $480 \mathrm{~nm}$ generates the colored open form $4 \mathrm{a}$ that reverts back to the cyclic form $3 a$ in the dark. ${ }^{13}$ The formation of the cyclic isomers is the unprecedented phenomenon for 1,3-indandione derived merocyanines, which behave as typical donor - acceptor conjugated systems. ${ }^{14}$ Moreover, we find that the photochemical properties of this compound and its analogs strikingly differ from the behavior of the hitherto known photochromic compounds. Here, we report on the synthesis, photochromic behavior, and X-ray structures of a series of derivatives of type $\mathbf{3}$.

Derivatives $\mathbf{3}$ were prepared by condensation of bindone $\mathbf{1}$ with the commercially available $p$-substituted cinnamic aldehydes 2 in acetic anhydride or ethanol in $42-90 \%$ yields as reddish $(\mathbf{3 a}, \mathbf{b})$ or yellow-orange $(\mathbf{3 c})$ crystals.

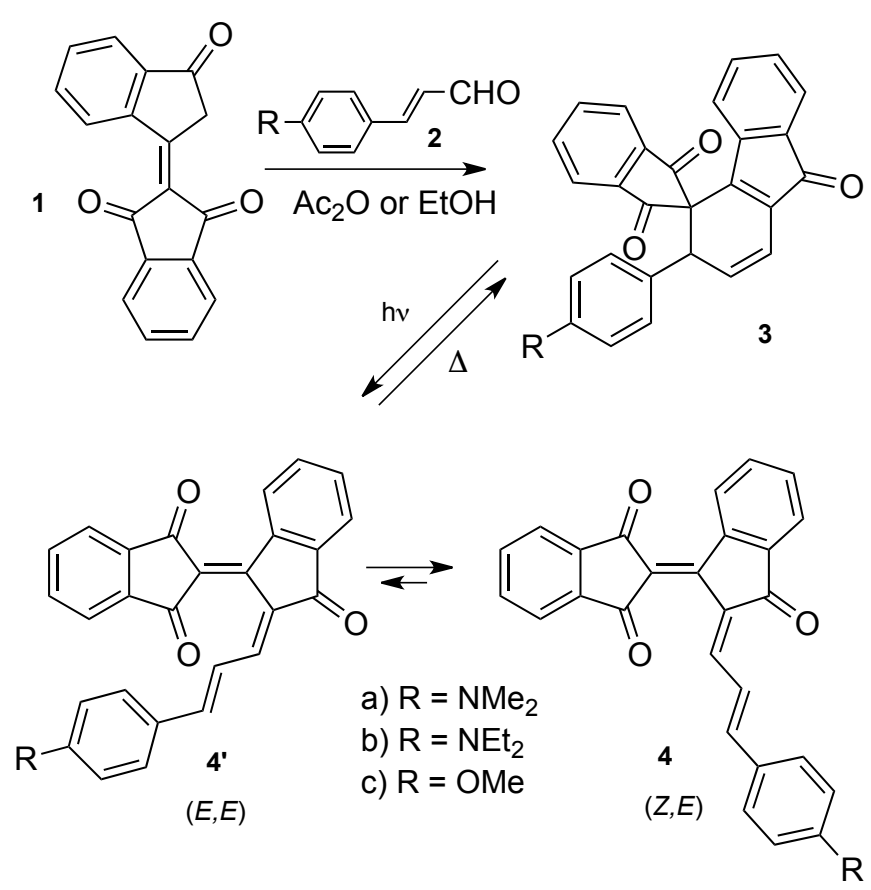

Scheme 1. Synthesis and photochromic conversions of derivatives $\mathbf{3}$.

The X-ray crystal structures ${ }^{\ddagger}$ were determined for derivatives $\mathbf{3 a}-\mathbf{3 c}$ (Fig. 1) and confirmed their cyclic forms. There 
are several short $\mathrm{C}-\mathrm{H}$...O intermolecular contacts in the range of $3.137-3.802 \AA$ (C...O distances), seven for $\mathbf{3 a}$, five for $\mathbf{3 b}$ and 15 for $3 \mathbf{c},+$ that correspond to the definition of the $\mathrm{C}-\mathrm{H} . . . \mathrm{O}$ hydrogen bond ${ }^{15}$. Each of the three carbonyl groups within 3a - 3c participate in the formation of $\mathrm{HBs}$, but although the $\mathrm{C}-\mathrm{H}$ counterparts are specific for each derivative, the phthaloyl $\mathrm{C}-\mathrm{H}$ atoms of the 1,3-indandione moieties (C16, C19 of 3a, C16 of 3b, C17, C45 of 3c) are always involved (Fig. 1). The presence of numerous $\mathrm{C}-\mathrm{H}$...O intermolecular $\mathrm{HBs}$ in the solid nonconjugated indan-1,3-dione derivatives giving rise to supramolecular aggregates is typical for these derivatives. ${ }^{16}$ We also showed that the presence of intra- and intermolecular $\mathrm{HBs}$ of this type can explain anomalies in the NMR spectra of bindone 1 and its analogs and of a series of isobenzofuranones also in solution. ${ }^{17}$
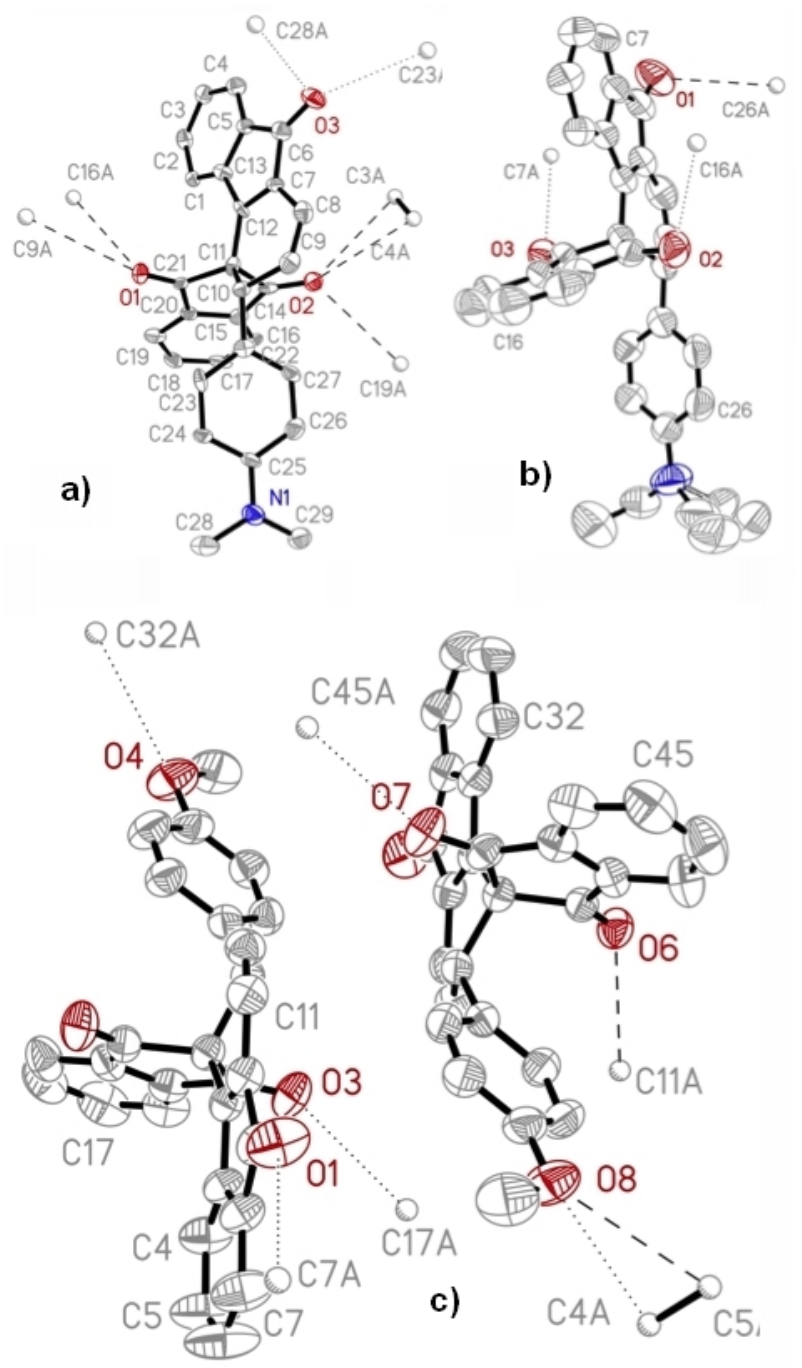

Fig. 1. ORTEP representations of the molecular structures of $\mathbf{3 a}(\mathrm{a}), \mathbf{3 b}(\mathbf{b})$ and $\mathbf{3 c}$ (c) with thermal ellipsoids ( $50 \%$ probability) showing short C-H...O intermolecular contacts. The shortest intermolecular distances $(\AA ̊))$, 3a: 3.137(12), O3...C28A, 3.216(11), O2...C3A; 3b: 3.183(4), O2...C16A; 3c: 3.1953(18), O7...C45A, 3.2107(18), O3...C17, 3.2263(19), O4...C32.

In solution, equilibrated in the dark for several hours, we detected the following isomer distribution for $\mathbf{3 a}, \mathbf{4 a}$ and $\mathbf{4}^{\prime} \mathbf{a}$, respectively: 83,10 and $7 \%$ in toluene $\mathrm{d} 8,89,8$ and $3 \%$ in $\mathrm{CD}_{2} \mathrm{Cl}_{2}, 96,3$ and $1 \%$ in $\mathrm{CDCl}_{3}$ and $98,2,0 \%$ in acetone $\mathrm{d} 6$. The presence of both $E, Z$ - and Z,Z-isomers in smaller quantities cannot be excluded, but their detection is limited by relatively low solubility of $\mathbf{3}$. Derivative c exists exclusively as cyclic isomer 3.

Electronic absorption spectra of derivatives $\mathbf{a}-\mathbf{c}$ in the visible range exhibit broad low intensity $\left(\varepsilon<800 \mathrm{M}^{-1} \mathrm{~cm}^{-1}\right)$ bands corresponding to absorption of $\mathbf{3}$ overlapped with absorption of some amounts of $\mathbf{4}$ in the case of $\mathbf{a}$ and $\mathbf{b}$ (Fig. 2). Solutions of $\mathbf{3 a}-\mathbf{c}$ are photochromic and sensitive even to ambient light. Initially, we assumed that the photochromic behaviour of $\mathbf{3}$ is analogous to that of the known spiroheterocyclic photochromes ${ }^{6}$. However, the expected acceleration of discoloration upon irradiation by green or red light did not occur and, moreover, led to the increase of the absorption of the photo-generated isomers. Thus, a rapid color change (Fig. 2) is observed upon irradiation of their solutions at any wavelength between 254 and $610 \mathrm{~nm}$ (3a), 254 and 642 $\mathrm{nm}(3 \mathrm{~b})$ and 254 and $532 \mathrm{~nm}$ (3c).

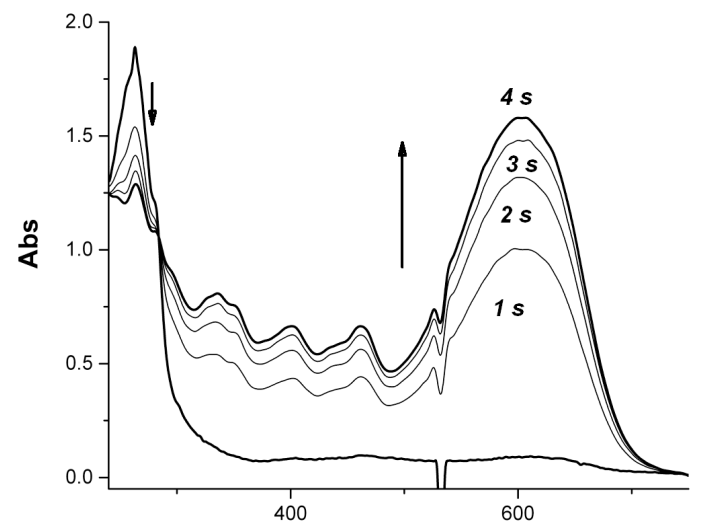

a)

$\lambda, \mathrm{nm}$

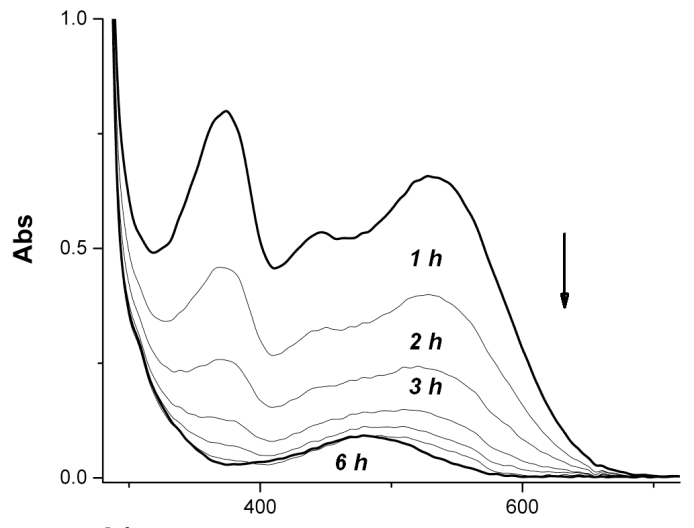

b)

$\lambda, \mathrm{nm}$

Fig. 2. a) Irradiation of $\mathbf{3 a}$ at $532 \mathrm{~nm}$ in $n$-octane; b) thermal discoloration of $\mathbf{4 c}$ in $\mathrm{CH}_{2} \mathrm{Cl}_{2}$ after irradiation at $532 \mathrm{~nm}$.

The rate of discoloration of photo-induced isomers $\mathbf{4}^{\prime}$ and $\mathbf{4}$ strongly depends on the temperature and solvent polarity. Thus, at room temperature, the discoloration rate constant of 4a changes by two orders of magnitude $\left(2.55 \times 10^{4} \mathrm{~s}^{-1}\right.$ in cyclohexane vs. $744 \times 10^{4} \mathrm{~s}^{-1}$ in methylene chloride) (Fig 3a). Replacement of the dimethylamino group by the diethylamino group (4a vs 4b) brings about not only a considerable bathochromic shift ( $20 \mathrm{~nm}$ in toluene), but also increases the 
discoloration rate by another order of magnitude (Fig. 3b). In protic solvents coloration can be observed only under irradiation and the colored forms disappear within few seconds after the light source is off. Complete restoration of the $4 \mathrm{c}$ spectrum takes about $6 \mathrm{~h}$ (in methylene chloride) and several days (in toluene). The colored forms rapidly disappear at elevated temperatures: in toluene, for instance, discoloration of $4 \mathrm{a}$ is almost instantaneous at $90-100^{\circ} \mathrm{C}$.

The MC forms are not photosensitive. Thus, $4 a$ cannot be generated by irradiation of $3 a$ at $642 \mathrm{~nm}$ in $n$-octane, since $\mathbf{3 a}$ practically does not absorb at this wavelength. On the contrary, absorption of $\mathbf{4 a}$ is still considerable here. Discoloration of $\mathbf{4 a}$, generated at $405 \mathrm{~nm}$, under permanent irradiation at $642 \mathrm{~nm}$, yielded the same discoloration rate constant as the dark measurements. The discoloration rate of 4c in methylene chloride was not affected by light at $642 \mathrm{~nm}$ as well.
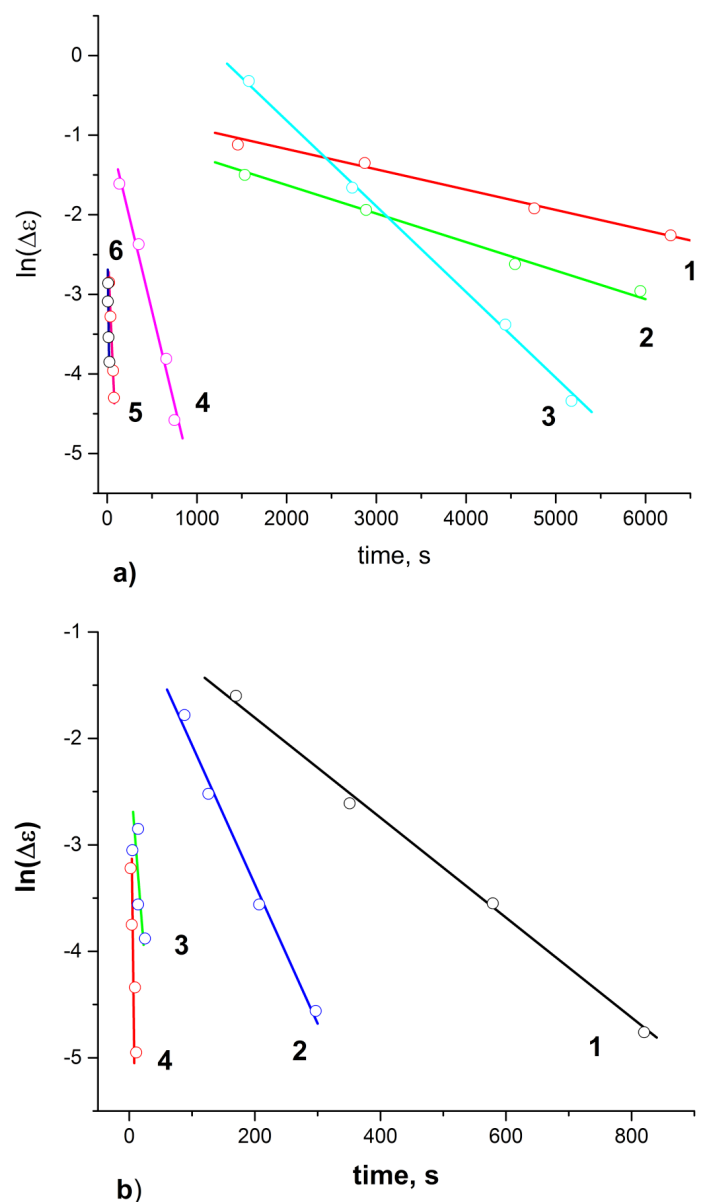

Fig. 3. Discoloration kinetics at $25^{\circ} \mathrm{C}$ of a) 4 a in different solvents $\left(k \times 10^{4} \mathrm{~s}^{-1}\right): 1$ cyclohexane (2.55), 2 - $n$-octane (3.33), 3 - toluene (10.8), 4 - THF (47), 5 - methylethyl ketone (258), $6-\mathrm{CH}_{2} \mathrm{Cl}_{2}$ (744); b) $\mathbf{4 a}$ and $\mathbf{4 b}\left(\mathrm{k} \times 10^{4} \mathrm{~s}^{-1}\right)$ : 1 - $\mathbf{4 a}$ in THF (47), $2-\mathbf{4 b}$ in THF (130), 3 - 4a in $\mathrm{CH}_{2} \mathrm{Cl}_{2}$ (744), 4 - 4b in $\mathrm{CH}_{2} \mathrm{Cl}_{2}$ (4810).

The photochemical inertness of the photo-induced isomers 4 is not unexpected, taking into account their behaviour as typical donor - acceptor conjugated systems with intramolecular charge transfer. Thus, strong positive solvatochromism of 4 (Fig. 4) confirms the presence of the efficient conjugation observed also with their nonphotochromic analogs ${ }^{14}$. The longest wavelength absorption band of derivative $4 a$ undergoes a $62 \mathrm{~nm}$ red shift in methylethyl ketone compared to the octane solution, confirming its nature as a charge transfer band. The electronic transitions of this kind are photochemically inert. For instance, the efficient conjugation between the electron donating and accepting moieties leads, in particular, to the loss of photochromism in fulgides. ${ }^{18}$

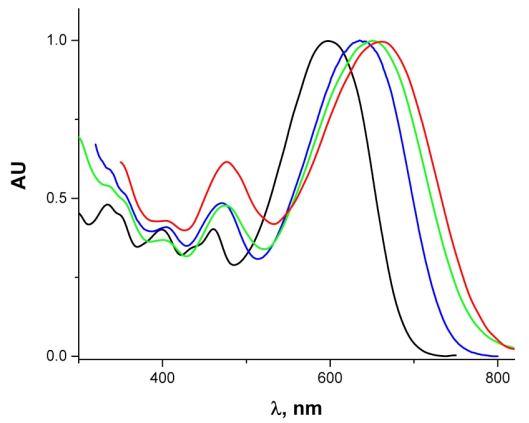

Fig. 4. Normalized absorption spectra of $\mathbf{4 a}$ in $n$-octane (black), toluene (blue), THF (green) and methylethyl ketone (red).

Repeating irradiation at $532 \mathrm{~nm}$ and thermal discoloration of $3 a-c$ for $10-15$ times did not reveal any noticeable fatigue features.

Quantum mechanical calculationst on the cyclic derivative 3a and all four isomers of the MC form using B3LYP/6$31 G(d, p) / / B 3 L Y P / 6-31 G(d, p)$ model chemistry showed that the most stable isomers are $4 a(Z, E)$, by $10.4 \mathrm{kcal} / \mathrm{mol}$ and 4 'a $(E, E)$, by $7.0 \mathrm{kcal} / \mathrm{mol}$ (ZPE corrected) more stable than cyclic 3a. Z,Z- and E,Z-isomers are the least stable, but still more stable than $3 a$ by 4.7 and $3.3 \mathrm{kcal} / \mathrm{mol}$, respectively. Calculations in methylene chloride increased the energy difference by about $1 \mathrm{kcal} / \mathrm{mol}$ in favor of the $M C$ isomers. Using the B3LYP/6-311G+(2d,p) basis set gave essentially the same results.

TD DFT calculations at the same model chemistry predicted that the first electronic transition within derivatives $\mathbf{3}(581 \mathrm{~nm}$, $f=0.009)$ is predominantly the HOMO - LUMO transition of the $\pi, \pi *$-type (Fig. 5). Upon excitation, charge transfer occurs from the electron donating aryl groups toward the neighboring electron accepting fluorenonyl and 1,3-indandionyl moieties. The low intensity longest wavelength absorption bands observed for derivatives $\mathbf{3}$ are thus through-space charge transfer bands in contrast to the MC-type isomers of 4 exhibiting intense through-bond charge transfer bands (549 $n m, f=0.7)$. The degree of charge transfer can be roughly evaluated by the change in the NBO charges of the $\mathrm{C}=\mathrm{O}$ groups. Thus, excitation leads to the increase in the sum of negative charges on the $\mathrm{C}=\mathrm{O}$ groups by $0.19 \mathrm{e}^{-}(\mathbf{3 a})$ and by 0.04 $e^{-}$for (4a).

The mechanism of the photochemical reaction is currently under investigation in our lab. Our preliminary results strongly suggest that the photochromic behavior of derivatives $\mathbf{3}$ may 
stem from at least partial retaining of the $\mathrm{HBs}$, observed in solid, also in solution.

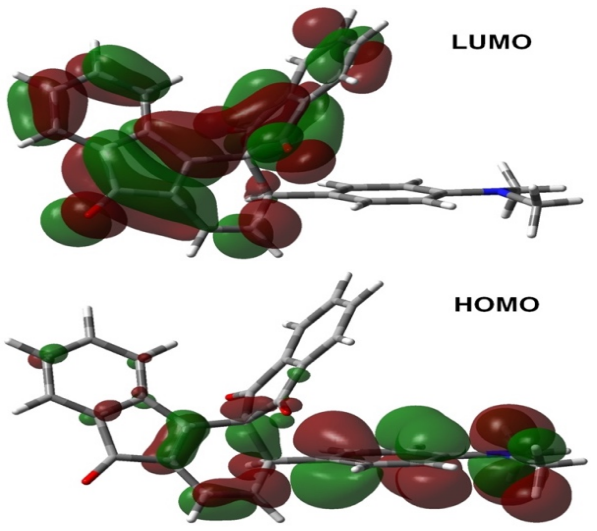

Fig. 5. HOMO and LUMO plots of $3 a$.

Derivatives $\mathbf{3 a}-\mathbf{c}$, as new photochromes, exhibit thus a number of unique features, such as sensitivity to both UV and visible light, the formation of the insensitive to light colored forms and a wide span of their thermal discoloration rates. The ability of these compounds to react with green and red light and strong dependence of the discoloration rates on the polarity of surroundings suggest their possible use for biomedical studies.

\section{Acknowledgements}

This work was supported in part by the Euripides/COSEC-ID project (No 102930210) from the Ministère de l'économie de l'industrie et de l'emploi.

\section{Notes and references}

¥ Crystallographic data for the structures reported in this paper have been deposited with the Cambridge Crystallographic Data Centre: 3a CCDC 1436240; 3b CCDC 1436241 and 3c CCDC 1436242.

1 A. V. Kulinich and A. A. Ishchenko, Russ. Chem. Rev., 2009, 78, 141.

2 S. R. Marder, B. Kippelen, A. K.-Y. Jen and N. Peyghambarian, Nature, 1997, 388, 845; A. Teshome, A. J. Kay, A. D. Woolhouse, K. Clays, I. Asselberghs and G. J. Smith, Optical Mater., 2009, 31, 575; U. Lawrentz, W. Grahn, K. Lukaszuk, C. Klein, R. Wortmann, A. Feldner and D. Scherer, Chem. Eur. J., 2002, 8, 1573.

3 A. Mishra, M. K. Fischer and P. Bäuerle, Angew. Chem. Int. Ed., 2009, 48, 2474; A. Zitzler-Kunkel, M. R. Lenze, N. M. Kronenberg, A.-M. Krause, M. Stolte, K. Meerholz and F. Wu rthner, Chem. Mater., 2014, 26, 4856; T. Meyer, D. Ogermann, A. Pankrath, K. Kleinermanns and T. J. Müller, J. Org. Chem., 2012, 77, 3704.

4 L. Huang, M. Stolte, H. Bürckstümmer and F. Würthner, Adv. Mater., 2012, 24, 5750

5 A. Toutchkine, W.-G. Han, M. Ullmann, T. Liu, D. Bashford, L. Noodleman and K. M. Hahn, J. Phys. Chem. A, 2007, 111, 10849; M. Li, X. Wu, Y. Wang, Y. Li, W. Zhu and T. D. James, Chem. Commun., 2014, 50, 1751; C. J. MacNevin, D.
Gremyachinskiy, C.-W. Hsu, L. Li, M. Rougie, T. T. Davis and K. M. Hahn, Bioconjugate chemistry, 2013, 24, 215.

6 Organic Photochromic and Thermochromic Compounds. Crano, J. C.; Guglielmetti R. J. Eds. Plenum Press, N.-Y. 1999; V. I. Minkin, Chem. Rev., 2004, 104, 2751; V. I. Minkin, Russ. Chem. Rev., 2013, 82, 1.

7 V. A. Lokshin, A. Samat and A. V. Metelitsa, Russ. Chem. Rev., 2002, 71, 893; J. D. Hepworth and B. M. Heron, in Functional Dyes, ed. S.-H. Kim, Elsevier, Amsterdam, 2006, p. 85.

8 O. Brede, L. Goebel, L. and T. Zimmermann, J. Phys. Chem. A, 1997, 101, 4103; L. Sanguinet, J. L. Pozzo, V. Rodriguez, F. Adamietz, F. Castet, L. Ducasse and B. Champagne, J. Phys. Chem. B, 2005, 109, 11139.

9 Y. Shiraishi, M. Itoh and T. Hirai, Phys. Chem. Chem. Phys., 2010, 12, 13737; J. Whelan, D. Abdallah, K. Piskorz, J. T. C. Wojtyk, J. M. Dust, J.-M. Nunzi, S. Hoz and E. Buncel, Phys. Chem. Chem. Phys., 2012, 14, 13684; Z. Tian, R. A. Stairs, M. Wyer, N. Mosey, J. M. Dust, T. M. Kraft and E. Buncel, J. Phys. Chem. A, 2010, 114, 11900.

10 D. G. Patel, M. M. Paquette, R. A. Kopelman, W. Kaminsky, M. J. Ferguson and N. L. Frank, J. Am. Chem. Soc., 2010, 132, 12568; Y. Shiraishi, M. Itoh and T. Hirai, Tetrahedron Lett., 2011, 52, 1515; S. Aiken, K. Booth, C. D. Gabbutt, B. Mark Heron, C. R. Rice, A. Charaf-Eddin and D. Jacquemin, Chem. Commun., 2014, 50, 7900.

11 G. Copley, J. G. Gillmore, J. Crisman, G. Kodis, C. L. Gray, B. R. Cherry, B. D. Sherman, P. A. Liddell, M. M. Paquette, L. Kelbauskas, N. L. Frank, A. L. Moore, T. A. Moore and D. Gust, J. Am. Chem. Soc., 2014, 136, 11994; P. Peng, P. Strohhecker and Y. Liao, Chem. Commun., 2011, 47, 8575; J. Buback, P. Nuernberger, M. Kullmann, F. Langhojer, R. Schmidt, F. Würthner and T. Brixner, J. Phys. Chem. A, 2011, 115, 3924; S. Helmy, F. A. Leibfarth, S. Oh, J. E. Poelma, C. J. Hawker and J. Read de Alaniz, J. Am. Chem. Soc., 2014, 136, 8169.

12 A. A. Beharry, O. Sadovski and G. A. Woolley, J. Am. Chem. Soc., 2011, 133, 19684; D. Bléger, J. Schwarz, A. M. Brouwer and S. Hecht, J. Am. Chem. Soc., 2012, 134, 20597; S. Samanta, A. A. Beharry, O. Sadovski, T. M. McCormick, A. Babalhavaeji, V. Tropepe and G. A. Woolley, J. Am. Chem. Soc., 2013, 135, 9777; Y. Yang, R. P. Hughes and I. Aprahamian, J. Am. Chem. Soc., 2014, 136, 13190.

13 B. Zinger, P. Schaer, G. Berkovic, G. Meshulam, Z. Kotler, L. Shapiro, R. Mazor and V. Khodorkovsky, SPIE Proceedings, 1997, 3135, 71.

14 G. Meshulam, G. Berkovic, Z. Kotler, A. Ben-Asuly, R. Mazor, L. Shapiro and V. Khodorkovsky, Synthetic Metals, 2000, 115, 219; A. Arjona-Esteban, J. Krumrain, A. Liess, M. Stolte, L. Huang, D. Schmidt, V. Stepanenko, M. Gsänger, D. Hertel, K. Meerholz and F. Würthner, J. Am. Chem. Soc., 2015, 137, 13524; J. Francos, S. E. García-Garrido, J. Borge, F. J. Suárez and V. Cadierno, RSC Adv., 2016, 6, 6858

15 Desiraju, G. R.; Steiner, T. The Weak Hydrogen Bond in Structural Chemistry and Biology. Oxford University Press, New York, 1999; S. Horowitz and R. C. Trievel, J. Biol. Chem., 2012, 287, 41576.

16 F. Orozco, B. Insuasty, J. N. Low, J. Cobo and C. Glidewell, Acta Cryst. C, 2008, 64, 0162.

17 M. Sigalov, A. Vashchenko and V. Khodorkovsky, J. Org. Chem., 2005, 70, 92; M. Sigalov, P. Krief, L. Shapiro and V. Khodorkovsky, Eur. J. Org. Chem., 2008, 673; C. Niebel, V. Lokshin, M. Sigalov, P. Krief and V. Khodorkovsky, Eur. J. Org. Chem., 2008, 3689.

18 P. J. Darcy, H. G. Heller, S. Patharakorn, R. D. Piggott and J. Whittall, J. Chem. Soc. Perkin Trans. I, 1986, 315. 